\title{
Article \\ PSYCHOANALYSIS VERSUS ADOPTION: ANALYTIC PARENTHOOD AND PARENTAL COUNTERTRANSFERENCE
}

\author{
Gianni Guasto ${ }^{1}$
}

As we know, Sándor Ferenczi compared the analytic and adoptive relationships as the psychoanalyst exercises a parental role to some extent. The author notes that a commonality between the adoptive relationship and the analytic one is that if the parental couple is burdened with painful counter-transferential experiences and feelings that have not been worked through, these can pose a danger for the strength of the newly developing parental relationship. In the analytic situation the analyst's position implies the risk of conflict with the parental internal objects resulting from the primary introjections, especially if the original environment was abusive or severely neglectful. Similarly, the adoptive family is often burdened with revengeful and competitive aggressiveness of their own introjected parental objects, having as a main task to keep unified the pre-adoptive autobiographical memories that were dissociated and interrupted. In such cases it is very important to give the adoptive parents help so as to cope with their difficult "countertransference," supporting them to reduce their sense of guilt and unsuitability to nurse their children, especially if the adoptive parents feel guilty because of their own infertility. In this paper the author describes two cases concerning both situations, emphasising the clinical risks and the evolutionary potentialities.

KEY WORDS: Ferenczi; Psychoanalytic relationship; Adoptive relationship; Countertransference; Bad introjected objects; Dissociated autobiographical memory

https://doi.org/10.1057/s11231-020-09264-w

\section{HISTORICAL CONTINUITY AND DISCONTINUITY IN SELF-EXPERIENCE}

Awareness of the historical continuity of existential experience is an undeniable requisite for the cohesion of the self. Frequent encounters with patients, who have undergone various types of caesura during their pre- and

Gianni Guasto, M.D., psychiatrist, training analyst of Società Italiana di Psicoanalisi e Psicoterapia "Sándor Ferenczi" (ISFN). Co-editor-in-chief of The Wise Baby/II Poppante Saggio rivista del rinascimento Ferencziano.

Address correspondence to: Gianni Guasto, M.D., via G. Mazzini 80/6 16031 Bogliasco (GE), Italy. E-mail: gguasto@me.com 
post-natal lives, increasingly highlight the ways in which the reunification of this experience becomes essential to the survival or the psychic birth of the subject.

Neuroscientists' discovery of an implicit fetal memory (Piontelli, 1992, 2006) and a postnatal one (Mancia, 2006) means that psychoanalysis must now confront the topic of recovering these memories, at least potentially (see also Korff-Sausse, 2009). If the study of the influence of prenatal caesura on the psychic development of those born prematurely is still at an initial stage, greater information can be obtained from the individual experiences of people who have undergone significant existential discontinuity during infancy. This is the case with adopted individuals who, after an initial separation from their biological mother, have gone through experiences of serious discontinuity of care, which have been stored at many, more or less conscious levels in their autobiographical memory.

The awareness of the problem of discontinuity in one's own life is crucial to understanding every subsequent psychopathological disorder. Margaret Little (1960), in her paper "On Basic Unity" says that such a sense of "discontinuity must be repaired before survival can be taken for granted" (p. 379). Unfortunately, such a reparation cannot be "taken for granted" in the totality of rejected and subsequently adopted children, because of the gap of time elapsing between their birth and the final family affiliation. In several cases the journey to the adoptive family is very long and bumpy, passing through institutes, fostering families, and so on.

We know that a firmly internalized parental object is the basis of a unified body, a foundation for later identifications, relationship to self and objects, and a sense of well-being and trust in the self. During early and late development, the unity of the self is damaged not only by disruptions in the continuity of care, but by the actual separation from the mother (who is the "past" of the subject, no matter the age when the separation occurs), as well as by the break from the native family, home, environment, family name (and even first name), country and tongue, as in the case of international adoptions. The continuity of one's own environment with parents and people with whom to grow is a basic condition of the construction of one's identity, which is jeopardized by every unbearable and incomprehensible loss and relocation, even in cases where the original conditions were unfavorable or abusive.

Such a caesura is a "jump in the darkness" that, using Ferenczi's findings (1932), we can expect could be substained by a benevolent force, Orpha, a kind of inner resilience, emerging from the depth of despair to save the psyche and can even accept madness in order to survive (Kelley-Lainé, 2016). This "guardian angel" (Ferenczi, 1932, p. 178), whose task is to maintain the unity of life experience, functions as an "assembler" of 
dissociated and fragmented parts of the self. Having such an internal "foster parent," means that every attempt to substitute a blood-kin family will have to be negotiated: "the analyst must, first and foremost, gain Orpha's trust and help her look after the dissociated injured parts" (Gurevich, 2016, p. 330).

Clinical practice demonstrates that the memory of traumatic experiences is subject to complex dissociative phenomena, which can disrupt the uniform continuity of the historical experience of the self, such that it is represented as a grouping of separate life fragments. The early life of a child who has been later adopted can continue parallel to, and independently from, conscious experience, like a second Ego alongside the principal identity, in a condition comparable to that of an individual in a coma. Sándor Ferenczi expresses this in a similar way when he describes those patients who "need to be adopted" by the analyst (1930, p. 124). In such cases, during an initial period of existence characterized by mistreatment and helplessness, the psychic apparatus puts vital forces ("Orpha") into play that try to compensate for the absence of an adequate caregiver. In his Clinical Diary (1932), Sándor Ferenczi extensively describes the native and self-containing forces which emerge even from the smallest fragmentation of a mind subjected to dissociative phenomena because it has been overwhelmed by unbearable traumas. If the process of scission and fragmentation is followed by the loss of conscious thought, organizing life instincts can emerge from its ashes.

The enormity of this suffering, plus helplessness and despair of any outside help, propel her [the patient] toward death; but as conscious thought is lost, or abandoned, the organizing life instincts ("Orpha") awaken and in place of death allow insanity to intervene. (Ferenczi, 1932, p. 8)

In the last couple of decades, several authors elucidated Ferenczi's Orpha principle and its multiple functions. For example, Smith (1999), in her groundbreaking rediscovery of Ferenczi's overlooked concept, refers to Orpha as a "life-organizing fragment of [the] personality" of a traumatized patient (p. 345, emphasis added). Vida (2005) calls Orpha a lost or abandoned capacity of an individual (p. 7, emphasis added), and Gurevich (2016), elucidates the functions of the "Orphic analyst" (p. 330). Soreanu (2017, p. 228, emphasis added) describes Orpha's "linking and un-linking" qualities, the continuities, and discontinuities.

There's no doubt that Ferenczi, theorizing the Orpha concept, found a way to describe, perhaps for the first time, a continuity thread in the interruption or even the fragmentation of the self. In both cases I will describe, the secret life of a dissociated part of the self, surfaced into consciousness within the relationship with a new "parental" figure. In 
Sophia's case, the repression of the experience of an abortion, an unnamable memory of her secret incestuous alliance with her father, was recovered as a baby's voice calling her every morning, while she was still half-asleep. In Anne's case, the dissociated part continued to live as a secret "twin," a residual son of her biological mother, whose task was to fight Anne and her new family into which she was re-born. Such a dissociated part was very actively engaged in a loyalty conflict, as a partisan of the blood-kin mother, who was imagined as a victim, mourning for her lost daughter.

Working for many years in the public health sector, in private practice, and in therapeutic communities, I have frequently seen people who, having been born into a family marked by deprivation, mistreatment, dysfunctional care, or violence, or have spent time in orphanages, are later placed into an adoptive family. For a long time, it has been accepted wisdom that the earlier those traumatic experiences occur, the less they become part of the autobiographical memory of the individual. Some infant research however shows that young children, and even infants, can recall memories of early experiences. For example, psychological research by Edwards (2000) describes infants as young as 13 months old recalling early events in their lives (p. 353). Edwards explains that it is crucial whether

enabling relationships were available, or not, to render events meaningful for the child. For the child that begins life in an environment characterized by instability, lack of continuity and often its potential for significant harm, where no enabling relationship is available to process events-which may well describe the early environment of many adoptees-it is not surprising that there remains an unprocessed swirl of unlinked fragments (p. 354).

It is also true, that there is a tenacious investment of early adoptees (under a year and a half old) in their adoptive parents, while later adoptees (18 months to 8 years of age) are more attached to their biological parents. Frankel (1991) explains that this divide in attachment most likely reflects the power and specificity of bonding prior to age two or three (p. 104).

Very surprisingly, the scientific literature on adoption shows "deficiencies in our understanding of the psychology and pathology of adoption," (Frankel, 1991, p. 91), and that the differences between early and late adopted children are studied in merely a statistical way, with little attention to the child's whole biography, to such an extent that "the subtle effects of adoption have not been quantified" (p. 91). Moreover, studies as accurate as Frankel's still emphasize that "the incidence of disturbance is higher for late adoptees than for early adoptees" (p. 92) and seem to not consider the very late age of adoption, as with Anne, the patient I will describe, who was 11 
years old at the first meeting with the new family. In the vicissitudes of her life, a whole range of factors is involved in her lack of autobiographical memory: her age at adoption, her early experiences of abuse and severe neglect, testifying in a trial against her biological mother, her experience of living in a community for neglected children. Much evidence showed that the first part of her life and the post-adoptive one were not lived as a whole, but rather as two different and separate lives.

\section{PSYCHOANALYTIC THERAPY AND ADOPTION}

Adoption and psychoanalytic therapy have many things in common. First and foremost, they both involve the care and nursing of an individual, so as to retrace or revisit the parental relationship. A decisive element that psychoanalytic and adoptive relationships share is countertransference. Adoptive parents are not immune from this; they must face it daily in a much more pervasive way than the analyst who has to grapple with it when a patient has had serious traumatic experiences. Facing an adopted individual, the adoptive parents must confront a subterranean and forgotten reality: that of the pre-adoptive parental relationship, which can be present in the memory of the subject whether that individual is adopted or in analysis.

Our clinical experience frequently brings us into contact with individuals adopted by "good enough" families, and who, having had a relatively normal post-adoption childhood, run into explosive adolescent crises. Moreover, these crises can endanger the endurance of the entire family, injuring the most secret vulnerability of the parents who may already be frustrated by their physical inability to procreate. Repeatedly with these cases, we see how the onset of adolescence calls into play forms of unconscious regret and secret collusion with the original mother figure, or those portions of the self that have dissociated yet survived in a comatoselike form. This does not mean that non-biological relationships cannot become real progeny with ties characterized by an attachment relationship. However, such a level of attachment cannot be a starting point but rather an objective to be constructed over time through a long and difficult process with hidden dangers.

Adoption is a long process which, hopefully, ends with the creation of definitive mutual recognition and attachment. In some ways this is comparable to the transplantation of biological tissues in which "rejection" is considered a constitutive and normal event. Rejection of the adoptive parents by the adoptee, manifested in sudden and unexpected ways, risks provoking adverse counter-reactions by the adoptive family, who may 
already be narcissistically wounded by its own illusions of having overcome, through simple legal action, their ancient and long-held frustration, deriving from their inability to procreate biologically.

\section{A STRUGGLE OF TWO INTERNAL FAMILIES}

In the first draft of my paper, this chapter was titled "A family romance overturned;" now I felt obliged to change such a title because it would be confusing for the reader. When we talk about a "family romance," our first thought may be of Freud's famous paper "Der Familienroman der Neurotiker" [Family Romances] (1909), in which an imaginary construction is described, usually defined as "mythopoetic" because it's related to the wish in blood-kin children to have been born into a family different from their actual one: a more rich, noble, powerful, important one, and in every case, with less disappointing parents. As Freud explains, this fantasy can function as a defense against Oedipal fantasies and a stimulus for the emancipation and de-idealization of the original family.

Following this Freudian thought, Sándor Ferenczi (1922, pp. 415-416) described an opposite imaginary situation he called "The 'family romance,' of a lowered social position," meaning a neurotic state contrary to the usual forms of the neurotic romance, in which the young children, instead of having a "fantasy of parental ennoblement ... feel much more at home with the peasant class ... than in their own more cultivated milieu."

Although being similar to the type described by Ferenczi, Anne's case is not a mere mythopoetic imaginary construction, but in a memory, more or less an unconscious memory because of the repression or dissociation of an actual past experience with her own blood-kin family. I describe such an internal situation as the resurgence of the original introjected bad object to defy and blame the new one. It is an internal "bloody war" for loyalty, moved by a sense of guilt and inner persecution; and at the same time a painful way to establish a new attachment relationship, on the condition that the adoptive family will be supported to cope with the negative transference in the child, therapeutically working on

the ambivalence of the adoptive parents, [who] may endow [the child] with responsibility for their own felt sense of failure, for example, their not being able to conceive, or identify him with their own unacceptable instinctual strivings and see him as deviant" (Frankel, 1991, p. 93).

Much more tragically, in Sophia's case it is the retaliation of the bad internal object which holds Sophia as a kind of "hostage," in a struggle with the 
analyst considered in his parental function. As a psychoanalyst and psychotherapist working with people with a traumatic past characterized by the non-spontaneous "ablation" ${ }^{2}$ of the parental figures, I have treated cases with serious conditions due to arising feelings of forced loyalty, collusion, and/or a code of silence, towards parental figures who have abandoned, traumatized, or abused them. Many of these abusive parents were separated from their infant or young children early on, and some may even have been reported to the authorities by their own children. Reemergence of the "teratoma" (Ferenczi, 1930, p. 123) or "secret twin," which survived in a comatose state, often leads to the construction of the "family romance" in its reverse formulation to Freud's concept (1909), aiming therefore at the rehabilitation of the biological parental figure who is now represented as the victim of persecution and in need of protection (see also Ferenczi, 1922).

\section{CLINICAL EXAMPLE: SOPHIA}

This case concerns the rejection of a parental figure, showing the vitality of introjected bad experiences and their ability to resurface when confronted with para-parental objects (in this case the analyst), perceived as substitutes and antagonists.

Sophia, a 45-year-old woman, had an extensive history of incest. Her father began consistently sexually abusing her when she was 4 years old until she turned 16, when Sophia suddenly stopped her father by threatening him with a knife. This incident happened 2 years after having an abortion of her father's child, a memory that re-emerged spontaneously in the course of the analysis. Sophia's parents tried to blame her pregnancy on one of her male friends, with whom, according to the patient, there had been nothing but a few kisses.

The father had abused Sophia for all those years with the connivance of Sophia's mother, who would say to her: "today your father is very nervous: go to calm his nerves." Furthermore, she remembered that in obeying such an exhortation to join her father, who was waiting for her, she fell down the stairs. Telling me this event, she expressed her doubt to have fallen voluntarily. When talking about the persistent sexual abuse and neglect she experienced throughout her childhood, Sophia recalled having dangerously walked alone amidst city traffic, without any oversight by her parents.

Sophia came to know of my clinical experience with children who had been sexually abused, and chose me to be her analyst after her previous analysis failed because of some major mistakes made by her former analyst. The first mistake occurred when Sophia described a vignette from her 
childhood: she was in front of the mirror, adorning her hair with some multicolored little hair clips, while her father was watching her fascinated. The analyst commented that Sophia's behavior was "seductive:" an inappropriate word to say to an abused girl (her sexual abuse began at the age of 4 , when the father suddenly forced her to perform oral sex) for the guilty feelings it could elicit.

Subsequently, Sophia, set a trap for her analyst: she sent an anonymous short message to his mobile, wishing him a nice birthday, acting as if an adult woman was sending the message. The colleague fell into the trap, answering in a complacent way without considering the identity of the sender. Sophia became furious, labeling him "a turkey cock" (a disdainful Italian idiom to define a tombeur de femmes), and then she decided to leave her analyst.

We can view her former analyst's interpretation as being in a confusion of tongues situation (Ferenczi, 1933), he enacted and colluded with her father, eroticizing her innocent behavior as her father had done, and in an unconscious identification with the aggressor (Ferenczi, 1933), she fulfilled the role. In so doing, she was also obeying her internalized bad objectmother who sacrificed Sophia to her father, now the analyst ("I will be a temptress because you see me this way") and then "stabbed" the analyst, so to speak, using a phallic phrase- "turkey cock," to stop him and get rid of him, as she had used the knife to threaten and stop her father.

As a result of this experience, she was sent to me by a colleague, who described me as an "expert" in treating childhood sexual abuse, trauma, and victims of sexual harassments; at the time, I had been working for many years in a Trauma Centre that specialized in the treatment of children who were severely abused and neglected. Two months after our first meeting, we started analysis which proceeded regularly for 2 years.

Sophia missed her last session right before the first summer break; it could certainly be seen as a means to postpone the break, because, as a consequence of the missed session, she was obliged to pay me the last month after a complicated exchange of e-mails, through a bank credit transfer. When we resumed after the vacation, she revealed that a few days before, she had sent a nude photo of herself, taken from behind many years before, to a man whom she had superficially known a long time ago and with whom she had then lost contact: an acting-out that was embarrassing and strange for herself. I was astonished because Sophia was not at all an attention-grabbing or seductive girl; she was somewhat plump and looked older than her age. Also, she was not hypomanic, nor did she give the impression of being patently inadequate.

She told me that her pose in the photo was very similar to the one in Venus at her Mirror by Velázquez (1647). I wondered if she had a secret 
desire that I would immediately run to look up the painting; obviously, I did. Observing it, I was struck by the fact that the female figure, lying down, completely naked, and portrayed from behind, is showing not only her back but her buttocks as well. I knew that Sophia's buttocks had been a particularly exciting object for her father.

My first conjecture was that sending the photo to a far-away friend might be considered an attempt to call me back from my vacation through a sexual offer. This was my interpretation of the whole performance. But as for the mirror, in spite of my wondering if that painting prompted Sophia's fantasy to spy on me from the couch, I did not explore it, being afraid of offering an untimely interpretation. Shortly afterwards, I realized that to control my movements was a real need and anxiety for her, because of her fear of being sexually harassed by me, as she later confessed when she interrupted the analysis (see below). After further meditation about the whole process a long time after, I wondered if the photograph sent to the long lost friend, could necessarily be interpreted as a mere transferencerelated acting-out, or also a "call" to her father, to re-establish a broken relationship. She may have been enacting the memory from age 4, when she is looking in the mirror and putting clips in her hair-she may have been wondering if I could admire her tenderly and keep my boundaries and become a different object than her father. Perhaps it was a test like the one she gave her first analyst. By not offering further, "penetrating" interpretations, and maintaining good boundaries, Sophia stayed in treatment a while longer.

Soon after, she began to tell me about Ferdinand IV, the King of Naples (1751-1825), who was also known as Re Nasone [King Big Nose], a historically important figure, who was famous for the pleasure he took in spending time among the lower class, speaking their dialect and sharing in their customs. Sophia (born and raised in Campania, a region of Naples), added that the king used to maintain excellent commercial relationships with the Republic of Genoa (the city where I am from and live in). Moreover, Sophia remembered that the nickname of the king, "nasone," was the same used in her family to make fun of her father, because of his big nose.

After listening to Sophia, I began to think that this was an attempt to mitigate the disquieting and mad image of her father that she had presented to me until this moment; I told her about my reflection not suspecting what could happen shortly thereafter.

For a long time, Sophia saw me as a "hero" capable of waging relentless war against pedophiles until, during a session, she confessed that she had experienced orgasm only once in her life during sexual intercourse with her father. The confession significantly changed the panorama of the analytical 
relationship, bringing to light a "secret alliance" between Sophia and her father, which could collapse under the arrows of the analyst-judge, an enemy of incestuous relationships.

In spite of the interpretative work aimed at clarifying such a fantasy, one month after this revelation, Sophia was diagnosed with cancer in the breast, the part of her body, the mamma, that her father seemed to prefer. The urgency of undergoing chemotherapy compelled Sophia to stop her analysis despite every effort to persuade her to remain. A few months after the end of analysis, she sent me this poem:

Nobody can grow / Neither with partisans / You cannot kill the Pharisees / To be a better Person / Heroes *the true ones* like / History compromise / In the History. / Hatred kills without / Justice / Hatred binds ... Forever. /

(...) / Yet Justice, / The true one / Never belongs in the absolute. /

(...).

The message hidden in this poem was that Sophia had identified me with the partisans fighting against the tyranny of her pedophiliac father. According to her, it was a losing and dangerous fight that she considered a therapeutic failure, which would have exposed her to a ferocious punishment. Her disease violently exploded and was felt by her to be paternal vengeance for her having asked for my protection, a behavior considered a betrayal. The identification with the aggressor, silent for a long time just like a tumor in a latent state, had suddenly surfaced in the moment she had remembered the shared orgasm with her father.

Being obligated to choose between the menace of death and loyalty to me as a defender (a kind of "St. George fighting against the dragon"), Sophia gave herself once again to her persecutor, having lost faith in my ability to protect her: a mistrust, unfortunately, corroborated by the facts. Furthermore, in our last session she told me: "I'm obliged to interrupt the analysis, because of the chemotherapy. I hope to return after the end of such a horrible nightmare. But, if I come back, I have a petition for you: no more lying on the couch, please. I've never said it, but I was unceasingly worried, fearing all movements of your chair, as if you would be joining me on the couch. Next time, if it will be, we'll have to meet face-to-face." I was very surprised to have never noted such a concern.

A long time after the interruption of Sophia's analysis, I wondered if the fantasy of my being a "hero," a "partisan" fighting against the tyranny of sexual abuse, was mostly mine; I saw that my countertransference rescue fantasy was confirmed by the poem she sent me. It took me until much later to realize that I had been trapped in a rescue fantasy (see Berman, 1997). 


\section{CLINICAL EXAMPLE: ANNE}

The following case describes a patient's serious inner conflict of loyalty between her biological and adoptive families.

Anne was born to a 16-year-old single mother who had herself been abused by her older sister's husband. When the child was just a few years old, her mother took Anne to the man who was abusing her at the time, in exchange for economic compensation; this man, in turn "re-rented" Anne to his accomplices. At the age of five, Anne told a teacher about this and after a long time she was separated from her biological family. At the age of eight, she entered in a specialized center for children with difficulties (an institution much more "humane" and a better holding environment than an orphanage), and her birth parents lost their parental rights when she was 10 years old; the following year she was adopted by a childless ${ }^{3}$ upper- $^{-}$ middle class Italian family.

Anne's adoptive parents soon noticed that she scratched her arms excessively and thus she was referred to a psychotherapist. She also didn't get along with her classmates whom she judged to be too "aristocratic." According to her first psychotherapist, Anne described her parents as if they were the royal family of Windsor.

As she approached the end of her high school studies, her states of increasing irritability made her parents absolutely powerless to control her uncontainable, hostile, and disruptive behavior. One summer, the family went on holiday to a hotel in the mountains. There, the 15-year-old Anne began a relationship with Matthew, a waiter in the hotel who was 12 years older than her. Following the establishment of this relationship, Anne's aggressiveness towards her parents became fierce, fueled by the young man who described her adoptive parents as parasites who took advantage of her. The young couple formed an alliance against Anne's adoptive parents. In a state of evident submission, Anne began recording her parents' conversations because Matthew "demanded" to be updated in detail about everything that took place at home.

That year, Anne failed her classes at school. Accompanied by Matthew, she went to the police accusing her parents of having "paid the teachers to make her fail." At the age of 16, Anne asked the social workers who had dealt with her adoption to find out whether "there are children who are taken away from their own families because they are too poor and are given to adoptive parents who paid for them." During her third year of high school she lived in a boarding school not far from her parents' house. At the end of her fourth year, Anne, now eighteen, deceived her parents and moved away with Matthew at $500 \mathrm{~km}$ from home, to the city where I practice. Shortly afterwards the family began to receive requests for compensation 
from a lawyer, for a claim of mistreatment which Anne had suffered at the hands of her adoptive parents. As she was now living in my city, she was referred to me for psychotherapy.

When I first met Frances, the adoptive mother, she told me that every time Anne visited home, she said she could not stay for more than 24 hours and that Anne cried both at the moment of leaving and on the numerous telephone calls she had with her mother during her journey to Matthew's home, feeling herself obliged to return to Matthew. In the first meeting I had with Anne, without her family, she told me that her adoptive family was good and affectionate and that she was very conscious of this fact; "Nevertheless," she added, "my parents can't expect me to become their clone. After my adoption, I've always lived in a beautiful and luxurious house and I've gone to schools for good people. But I'm not like them." From our first session, Anne described her relationship with Matthew as cold and without passion. In the paranoid and parasitic climate of Matthew's family, where she chose to live, certainly not for love or physical attraction, I saw some similarities with the conditions of neglect, degradation, violence, and exploitation which she had known as a child. Could her present behavior be the reparation for a sense of unconscious guilt for having accused and left her biological mother? Might this be a late attestation of coerced loyalty to a criminal birth mother who must have asked, explicitly or not, for her silent complicity?

At this point, I felt it important that she consciously bring back to mind, more completely, all that she remembered about her own life before adoption, about which I had obtained a detailed description from Social Services. When I shared this information with Anne, she discovered she remembered many more things. Shortly afterwards, she decided to return to her adoptive family. From then on we had weekly psychotherapy sessions via Skype.

\section{AVATARS}

After Anne's homecoming, our weekly sessions via Skype rapidly became empty and meaningless. Anne was very silent, obliging me to ask her some general questions followed by insignificant answers. I was very frustrated.

Thinking of Anne's inner conflict about loyalty towards her biological mother, I became persuaded that my position as a "parent" was as an "unwanted third party" between Anne's original family and her adoptive one. From this perspective, in my opinion, Matthew had played the role of an avatar of the early rejected and newly returned mad blood-kin mother. 
At the same time, my conversations with Anne's adoptive mother, Frances, became more frequent so that the family could understand Anne's restless behavior, and her need to stay far from home for so many hours of the day. Very soon, she met another boyfriend, Eugene, with whom she spent many hours during the day and often during the night. Frances was very sad: she was feeling that her bond with her daughter was too tenuous and very incompletely realized. Frances and I were sharing a common thought that the relationship between Anne and Eugene would also be cold and devoid of passion, as it had been with Matthew.

It seemed to me that Anne's purpose was to establish distance from her adoptive mother (so gratifying the bad internal one): remaining for a long time in the company of a guy within an indifferent relationship, Anne seemed to have chosen a second avatar of her biological mother, now without paranoia, but passively complying with her "need" to be indemnified.

Within a short time, Anne provoked an argument between Eugene and her parents over something trivial, thus remaining neutral, as if she felt the need to remain outside the struggle between the internalized bad mother and the new one. This was a further stage of her journey to affiliation.

\section{A KIND OF "SUPERVISION"}

In the meantime, my work as a "supervisor" of Frances continued, to help the adoptive family avoid frustration or become overwhelmed by Anne's aggressive projections, with the task of helping the mother distinguish between her daughter's aggressions due to Anne's own internal conflicts, and Frances' own "countertransference" to the aggressive projections.

The decision to have closer, explicit, and frequent contact with the family of a minor is usually discouraged in psychoanalytic theory and practice but there was a different need here, although it still required strict confidentiality on everyone's part. I considered it a priority in this situation to make the parents aware of the deeper meanings of their child's hostility, (in proportion to their capacity to understand). In a way it was similar to supervision. It seemed crucial that Anne's un-worked-through issues not signal her parents' ineptitude and thereby risk the adoption stabilization process before it had truly begun. So far, there has been no reason to regret this somewhat unorthodox therapeutic strategy. ${ }^{4}$

From the beginning of my relationship with Anne's adoptive parents I met with the father a few times, however, he preferred that his wife handled these tasks. In talking with Frances, her deep emotions in the relationship with Anne became more and more urgent, and she asked me to establish a 
real therapeutic relationship with her, via Skype. All my attempts to refer her to a psychotherapist near her home were refused; Frances felt that we had uncovered deep emotions related to her own mother, and that it was worth continuing.

\section{THE ADOPTEE AND THE ANALYST IN THE CLASH OF INTROJECTIONS}

Zuckerman and Buschsbaum (2000, p. 11) write that "several authors discuss a common dynamic, the intense anger at both biological and adoptive parents, which can be projected (Brinich, 1990; Kernberg, 1985) and displaced (Sherick, 1983) onto the therapist."

They explain that just as in the adoptive relationship, the adoptee may present with a negative therapeutic reaction,

the adoptee patient may be suspicious of the analyst's motives and doubting the therapeutic affective milieu. Countertransferentially, the analyst may experience anger, rejection, and fantasies of abuse. The therapist may feel anxiety, a strong sense of rejection, and anger as a result of intense affective states that are projected and displaced onto the therapist and triggered by the analyst's own vulnerabilities as well. When anger predominates in the countertransference, the therapist could feel like the abuser the patient feared but constructed at the same time. When awash in rejection by the adoptee patient, the therapist could feel the profound disruptions she presumably knew so well (Zuckerman \& Buschsbaum, 2000, p. 11).

Identical reactions, though unconscious, unmanageable and unhelpful with a lack of psychoanalytic comprehension, often hint at the adoptive parents' inability to cope, because of their frustration for not being a fertile couple or for the disillusionment of not having achieved an idealized status of good parenthood.

\section{TRANSFERENCE AND COUNTERTRANSFERENCE WITH ADOPTED PATIENTS}

Transference in adopted patients has a peculiar condition determined by the actual substitution of caregivers. "Various authors depict the adoptee's defensive mission to preserve her biological parents as good objects and avoid the greater pain of knowing their limitations" (Zuckerman \& Buschsbaum, 2000, p. 12).

In a different situation, the analyst might be seen as an idealized object who is always perfect, never hurtful and does not make any errors. The adoptee may deny feeling hurt by, or be quick to blame herself for, the 
mistakes or mis-attunements that inevitably happen in the treatment. The analyst's countertransference may include "fears of abandoning and disappointing the patients in the face of their intense and poignant longings" (Zuckerman \& Buschsbaum, 2000).

Given the adoptee's painful early history, along with intense pressure on the therapist to be the good restorative object, there is persistent countertransferential fear of repeating the patient's traumatic past, particularly given the therapist's circumscribed role in the patient's life. It reminds us of the fragility of both the therapeutic connection and other relationships in the patient's life. At other times, countertransferentially, [the therapist feels] the desire to reject [the patient] owing to [the therapist's] extreme discomfort at her efforts to get inside of the therapist, physically and emotionally, and to idealize the therapist. In general, the feeling states are intense and shifting for both the patient and the analyst (Zuckerman \& Buschsbaum, 2000, p. 18).

Tubero (2002) writes about a powerful identification with a patient, in addition to experiencing discomfort about a patient's idealizing transference, where the patient assigned much power to the analyst. In response, there was a countertransferential desire to demystify the analytic role, based on the realization that the patient mistrusted and had difficulty with authority figures, such as her mother (p. 46). Feeling sorry for the adopted patient the analyst charged less than other patients with the same means (Sirois, 2014).

\section{THE ADOPTIVE PARENTS' TREATMENT}

According to Brinich (1980),

The treatment of adopted children usually cannot be divorced from the treatment of the adoptive parents because adoption is almost always linked in the parents with powerful affects and conflicts related to the issues of infertility, illegitimacy, and parenthood. Beyond these, the adoptive parents need to be able to deal with the ambivalence of their children without resorting to externalization and projection. ... While the child is loved, he is also representative of the parental failure to conceive. (pp. 125-126)

Usually, the support to blood-kin parents of young patients is given at monthly intervals or even less frequently; but, in my experience, problems such as the ambivalence of adoptive parents, often need more frequent therapy, especially those who

may subsume the child into their own conflicts [and/or] endow him with responsibility for their own felt sense of failure, for example, their not being able 
to conceive, or identify him with their own unacceptable instinctual strivings and see him as deviant (Frankel, 1991, p. 93)

In fact, a primary goal of the adoptee's therapy is to manage "a mourning process in which the child progressively modifies his conviction that he unequivocally belongs with adoptive parents" (Brinich, 1986, cited in Frankel, 1991, p. 93), having reached a secure attachment relationship after a long, painful, and dangerous journey.

To avoid the catastrophic risk of a collapse and dissolution of the adoptive bond, threatened both by the adoptee's "negative transference" towards the new family and by the parents' inability to cope with that, as well as their own countertransferences, psychotherapists have to help them to distinguish their own personal conflicts with parenthood from their child's projective hostility.

\section{A PROVISIONAL EPILOGUE}

Recently, Frances told me that Anne (now in her mid 20s) suddenly changed her daily habits as a consequence of the Covid-19 Pandemic lockdown established in Italy from March through June 2020. While up till then Anne used to spend much of her time away from home, during the lockdown she stayed home all the time. Moreover, after having always refused all forms of physical contact with the mother, during a recent day spent at the beach with both of her parents, Anne asked her mother to smear her whole body with sun block. Frances told me that Anne seemed to enjoy this very much. I found this information very interesting, and thought of Esther Bick's (1968) work on "The Experience of Skin in Early Object-Relations," and of Anne's need to recover her lost vital experiences.

In the meantime, Frances discovered her conflict with her own mother, having experienced her hostility at Frances' pursuit of motherhood. "When Anne went to live with Matthew," she explained to me, "I was persuaded that such a destiny was a punishment for having wanted to be a mother at all costs; I was feeling condemned to remain a childless woman, for having disobeyed my mother's prohibition." So, my therapeutic relationship with Frances is now continuing via Skype.

\section{CONCLUDING THOUGHTS}

The comparison between the two cases cited shows how, from parental ablation following mistreatment, abuse, or incestuous violence, a link of 
coerced loyalty to introjected evils can persist and they can be capable of drawing the subject back to itself and mobilizing it against protective figures later encountered.

As for my limitation in Sophia's case, I think it was due to my being identified as a good, repairing force, an alternative figure opposing a violent and abusing father without considering the persistence of the evils introjected in the crypt of the self. This status is the same one lived by the adoptive parents, often too easily identified as a saving force, against which any contrasting reaction becomes unexpected. This attitude, which adoptive parents can have, is not less "countertransferential" than the analyst's. Yet it needs to be recognized to prevent expulsive reactions.

Upon meeting Anne's parents, I had the good fortune to encounter an emotional environment particularly sensitive and favorable to taking on their daughter's experience in its entirety, and to considering her connection to a sadistic internalized object; they managed, with a little help, to tolerate their feelings of inadequacy due to their inability to have children, without being excessively frustrated.

As stated earlier, the analyst who deals with a neglected or abused subject has to face an internal caregiver ("Orpha") who has accompanied and taken care of the subject during the long night of solitude and dissociation; this caregiver, being more familiar than we are with the patient's death experience, usually compromises on it more easily. The analyst must deal with this; to repeat what Gurevich (2015) has said:

For the dissociated parts, to revive and reconnect intra-psychically and for true inter-subjective contact to be restored, helplessness and despair must be experienced (and not dissociated) with an empathic and containing other. Transformation occurs only when Orpha relinquishes her hold over the dissociated psyche, trusts the analyst to join her, surrendering her exclusive role and place, and the therapist takes over its reviving functions, though not, now, at the cost of emotional detachment. This includes acknowledging his own failures and their intra-psychic re-traumatizing impact on the patient. These, I suggest, are the analyst's Orphic functions (pp. 50-51).

The therapeutic work is obliged to tap into the adoptive parents' Orphic functions, such as their ability to be life-organizing in a traumatized child, and their inner resilience. Together, the analyst and adoptive parents discovered their adopted daughter's abandoned capacities. And, last but not least, therapy helped them to provide linking and continuities for her, which then they could "lend" to their adopted child. 


\section{ACKNOWLEDGEMENTS}

I am grateful to the editorial team of the American Journal of Psychoanalysis for their scrupulous and assiduous work and enlightening clinical perspectives.

\section{NOTES}

1. Gianni Guasto, M. D., is psychiatrist, psychotherapist, training analyst of Società Italiana di Psicoanalisi e Psicoterapia, "Sándor Ferenczi" (SIPeP-SF/ISFN). He is the Co-Editor-in-Chief of The Wise Baby/ll Poppante Saggio, rivista del rinascimento Ferencziano, published by Arpa edizioni (Italy).

2. By "ablation," I mean something similar to what Charles Rycroft (1965-1973) (Borgogno, 2010), described in which the "discontinuity in the family tree" (Borgogno \& Cassullo, 2010, p. 131) is shown as a need and a fantasy of the subject, himself, and not a reality imposed by the outside world, (e.g., by court mandate, as in Anne's case). Both cases discussed in this paper have nothing to do with a situation in which ablators "subordinate memory to mythopoesis" or "seek out ideal ancestors to replace the actual ones" (Borgogno \& Cassullo, 2010, pp. 129-130), but with the real content of a dissociated memory coming back as persecutor. Regarding the lack of memory in such an uprooted individual: "all events assume for the patient a characteristic sense of unreality, losing in memory any kind of affective meaning, so that ... the parental figure is perceived as a 'foreign body' that can neither be wholly integrated nor eliminated from the psyche ... and which therefore survives in dissociated areas of the mind exercising from this place-or rather 'nonplace'-an unconscious influence on the patient's life" (Borgogno \& Cassullo, 2010, p.133).

3. At the age of thirty, the future adoptive mother was suddenly affected by an unexpected early menopause.

4. However, the psychoanalysts Kerry Kelly Novick and Jack Novick (2005) have been treating children by working with the parents, sometimes exclusively; see their book Working with Parents Makes Therapy Work.

\section{REFERENCES}

Berman, E. (1997). Hitchcock's Vertigo: The collapse of a rescue fantasy. International Journal of Psycho-Analysis, 78, 975-988.

Bick, E. (1968). The experience of the skin in early object-relations. The International Journal of Psycho-Analysis, 49, 484-486.

Borgogno, F. (2010). (Issue Editor) Special Issue: The life and work of Charles Rycroft. American Journal of Psychoanalysis, 70(2), 109-206.

Borgogno, F. \& Cassullo, G. (2010). "Ablation of the parental images": A secret core in Charles Rycroft's psychoanalytic thought. American Journal of Psychoanalysis, 70(2), 128-138.

Brinich, P. M. (1980). Some potential effects of adoption on self and object representations. Psychoanalytic Study of the Child, 35, 107-133.

Brinich, P. M. (1990). Adoption, ambivalence, and mourning: Clinical and theoretical inter-relationships. Adoption \& Fostering, 14(1), 6-17. 
Edwards, J. (2000). On being dropped and picked up: Adopted children and their internal objects. Journal of Child Psychotherapy, 26(3), 349-367.

Ferenczi, S. (1922). The "family romance" of a lowered social position. In S. Ferenczi (Ed.) Further contributions to the theory and technique of psychoanalysis. (pp. 413-416). London: Karnac Books. 1994.

Ferenczi, S. (1930). The principles of relaxation and neocatharsis. In S. Ferenczi (Ed.) Final contributions to the problems and methods of psycho-analysis. (pp. 108-125). London: Karnac Books. 1994.

Ferenczi, S. (1932). The clinical diary of Sándor Ferenczi. J. Dupont (Ed.), M. Balint \& N.Z. Jackson (Trans.) Cambridge, Mass. \& London: Harvard University Press. 1988.

Ferenczi, S. (1933). On the confusion of tongues between adults and the child. In S. Ferenczi (Ed.) Final contributions to the problems and methods of psychoanalysis. (pp. 155-167). London: Karnac Books. 1994.

Frankel, S. A. (1991). Pathogenic factors in the experience of early and late adopted children. Psychoanalytic Study of the Child, 46, 91-108.

Freud, S. (1909). Family romances. Standard Edition, Vol. 9, (pp. 237-241). London: Hogarth.

Gurevich, H. (2015). The language of absence and the language of tenderness: Therapeutic transformation of early psychic trauma and dissociation as resolution of the "identification with the aggressor." Fort Da, 21(1), 45-65.

Gurevich, H. (2016). Orpha, Orphic functions, and the Orphic analyst: Winnicott's "regression to dependence" in the language of Ferenczi. American Journal of Psychoanalysis, 76(4), 322-340.

Kelley-Lainé, K. (2016). The economy of the totalitarian mind: The case of the immigrant child. American Journal of Psychoanalysis, 76(4), 376-388.

Kernberg, P. F. (1985-1986). Child analysis with a severely disturbed adopted child. International Journal of Psychoanalytic Psychotherapy, 11, 277-299.

Korff-Sausse, S. (2009). La première demeure. Les traces du prénatal [The first home. Traces of the prenatal]. Champ Psychosomatique, 56(4), 183-197.

Little, M. (1960). On basic unity. International Journal of Psycho-Analysis, 41, $377-384$.

Mancia, M. (2006). Implicit memory and unrepressed unconscious: How they surface in the transference and in the dream. In M. Mancia (Ed.), Psychoanalysis and neuroscience. (pp. 97-123). Milan: Springer.

Novick, K. K. \& Novick, J. (2005). Working with parents makes therapy work. Plymouth, UK: Rowman \& Littlefield Publishers, Inc.

Piontelli, A. (1992). From fetus to child: An observational and psychoanalytic study. London: Routledge. 2003.

Piontelli, A. (2006). On the onset of human fetal behavior, In M. Mancia (Ed.), Psychoanalysis and neuroscience (pp. 391-448). Milan: Springer.

Rycroft, C. (1965-1973). On ablation of parental images, or the illusion of having created oneself. In C. Rycroft (Ed.), Psychoanalysis and beyond. (pp. 214-232). London: Hogarth Press. 1985.

Sherick, I. (1983). Adoption and disturbed narcissism: A case illustration of a latency aged boy. Journal of the American Psychoanalytic Association, 31(2), 487-513.

Sirois, F. (2014). The personal myth: A re-evaluation. International Journal of Psycho-Analysis, 95(2), 271-289.

Smith, N. A. (1999). From Oedipus to Orpha: Revisiting Ferenczi and Severn's landmark case. American Journal of Psychoanalysis, 59(4), 345-366. 
Soreanu, R. (2017). Something was lost in Freud's beyond the pleasure principle: A Ferenczian reading. American Journal of Psychoanalysis, 77(3), 223-238.

Tubero, A. M. A. (2002). Adoption, attachment, and reenactment in the therapeutic setting: A case study of an adolescent girl. Journal of Infant, Child \& Adolescent Psychotherapy, 2(1), 39-65.

Velázquez, D. R. S. (1647). Venus at her Mirror. [Oil Painting]. London: National Gallery.

Vida, J. E. (2005). Treating the "wise baby." American Journal of Psychoanalysis, 65(1), 3-12.

Zuckerman, J. R. \& Buschsbaum, B. (2000). Strangers in a strange room: Transference and countertransference paradigms with adoptees. Journal of Infant, Child \& Adolescent Psychotherapy, 1(4), 9-28.

Publisher's Note Springer Nature remains neutral with regard to jurisdictional claims in published maps and institutional affiliations. 